\title{
Did You Finish Your Meal Today?
}

\section{Carol S. K. Lin*}

School of Energy and Environment, City University of Hong Kong, Hong Kong

Do you know how much high quality food is disposed every day? The answer is incredible, 3,300 tonnes alone in Hong Kong! This is a scaring figure and gets even more scaring when you think of all the people starving day by day on earth.

People have to think of all the food they throw away. However, convincing people to produce less food waste is difficult. It is expected from the food industry to produce and supply food in excess so that consumers can choose between qualities and even more important between prices. It could be so easy to produce less food waste but all people have to change their behaviour and only buy and prepare that food they are going to eat. That's basically all what needs to be done and the food industry will respond fast and adjusts its production to the consumer needs. However, such a change in consumer behaviour takes a long time. But what can be done with all the food waste appearing in the meantime? Should it just be disposed, composted, or used for biogas production? No, it shouldn't! Food waste is a valuable material and it has to be exploited totally.

But why is food actually valuable even when it has been thrown away? From a chemical point of view food waste is a mixture of mainly carbohydrates and proteins which can be degraded to glucose and amino acids, respectively. Once food waste has been degraded to glucose and amino acids both can be used as nutrients for microorganisms (bacteria, fungi, and algae) in biotechnological processes. Microorganisms take up the glucose and amino acids and convert both into utilisable biomass and products. For example, algal biomass from heterotrophic microalgae which grow well on nutrients from food waste is convertible into many products (e.g. fuels, food, and feed).

It is know that fossil oils are limited and the search for new sources to cover the demand of energy is challenging. Algal oils, present in microalgal biomass and convertible into fuels (e.g. biodiesel), are considered to partly replace fossil oils and as an environmentally friendly energy source in the future. Additionally, microalgal biomass has a high nutritional value due to the carbohydrates and proteins and can be used directly as food and feed. Algal biomass further contains polyunsaturated fatty acids needed for brain development of infants and highly wanted by food industry. Therefore microalgae provide not only energy in form of fuels but also an opportunity to recycle food waste into new high qualitative food.

To conclude, even when food waste serves as a source for nutrients for the production of fuels, and food and feed, the major goal should be zero tonnes of food waste produced every day by you.
*Corresponding author: Carol S. K. Lin, School of Energy and Environment, City University of Hong Kong, Hong Kong, E-mail: carollin@cityu.edu.hk

Received November 29, 2012; Accepted November 29, 2012; Published November 30, 2012

Citation: Lin CSK (2013) Did You Finish Your Meal Today? J Food Process Technol 4: e115. doi:10.4172/2157-7110.1000e115

Copyright: $\odot 2013$ Lin CSK. This is an open-access article distributed under the terms of the Creative Commons Attribution License, which permits unrestricted use, distribution, and reproduction in any medium, provided the original author and source are credited. 